\title{
Gender effect on quality of life in hemodialysis patients
}

\author{
Behzad Einollahi $\cdot$ Mohsen Motalebi
}

Received: 15 October 2013/Accepted: 19 November 2013/Published online: 6 December 2013

(C) Italian Society of Nephrology 2013

\section{Dear Editor,}

We read with interest the article by Peng et al. [1] entitled "Women on hemodialysis have lower self-reported healthrelated quality of life scores but better survival than men" published in your esteemed journal. In this study, females had poor self-reported health-related quality of life (HRQoL), but better survival than men [1]. We have also found a lower quality of life (QoL) score in women among 6,930 HD patients [2].

Peng et al. [1] mentioned that the higher prevalence and severity of psychological disorders in females cause poorer HRQoL in women than in men. On the other hand, women are more capable than men in providing and getting emotional support. Fife et al. [3] have also shown that women benefit more from family support, but men get more support provided by health care professionals. It is fact that health care professionals are not as eagerly available as family members to provide the patient's needs.

It is important to note that Peng et al. [1] did not look at some confounding factors that can influence HRQoL such as patient's education, work status, sex function, marital state and etc. We showed a correlation between educational level and work status with QoL [2].

Although Peng et al. [1] revealed that men had better HRQoL, women had significantly lower mortality than men. However, HRQoL score may be applied to forecast the risk of important outcomes such as death and previous studies have indicated that lower HRQoL in dialysis patients had strong relationship with higher mortality [4]. It may be due to some other factors which are more prevalent in men and were not detected in the current study [1] such as cigarette smoking, hypertension, viral hepatitis [5] and other chronic illnesses that cause a higher mortality rate in men.

Conflict of interest The authors declare no conflicts of interest.

\section{References}

1. Peng YS, Huang JW, Hung KY et al (2013) Women on hemodialysis have lower self-reported health-related quality of life scores but better survival than men. J Nephrol 26:366-374

2. Rostami Z, Einollahi B, Lessan-Pezeshki M et al (2013) Healthrelated quality of life in hemodialysis patients: an Iranian multicenter study. Nephro Urol Mon 5:901-912

3. Fife BL, Kennedy VN, Robinson L (1994) Gender and adjustment to cancer. J Psychosoc Oncol 12:1-21

4. Kojima M (2012) Epidemiologic studies of psychosocial factors associated with quality of life among patients with chronic diseases in Japan. J Epidemiol 22:7-11

5. Rostami Z, Lessan Pezeshki M, Soleimani Najaf Abadi A, Einollahi B (2013) Health related quality of life in Iranian hemodialysis patients with viral hepatitis: changing epidemiology. Hepat Mon 13:9611

B. Einollahi · M. Motalebi $(\square)$

Nephrology and Urology Research Center, Baqiyatallah

University of Medical Sciences, Molla Sadra Ave, Vanak Sq.,

Tehran, Iran

e-mail: dr.motalebi@ymail.com 